\title{
Medical schools receive $\$ 5$ million to support trainees during pandemic
}

- Cite as: CMAJ 2020 May 11;192:E523. doi: 10.1503/cmaj.1095866

Posted on cmajnews.com on April 24, 2020

$\mathrm{T}$ he CMA Foundation (CMAF) will donate more than $\$ 5$ million to Canada's 17 medical schools to support medical students and residents who are facing financial difficulties due to the coronavirus disease 2019 (COVID-19) pandemic. The grant is part of $\$ 20$ million in targeted funding for Canada's COVID19 response recently announced by the foundation.

Medical schools have seen an uptick in requests for financial assistance from trainees since the pandemic hit Canada, said
Allison Seymour, president of CMAF. "We heard from one of our partners, the University of Manitoba, that they had opened an emergency relief fund... within seven hours they had over 1000 applications."

The situation is particularly difficult for trainees supporting families, Seymour said. "If a spouse has just lost their income, that's an additional financial stress."

The Association of Faculties of Medicine of Canada welcomed the donation. According to president and CEO Dr. Geneviève Moineau, the funds are being distributed

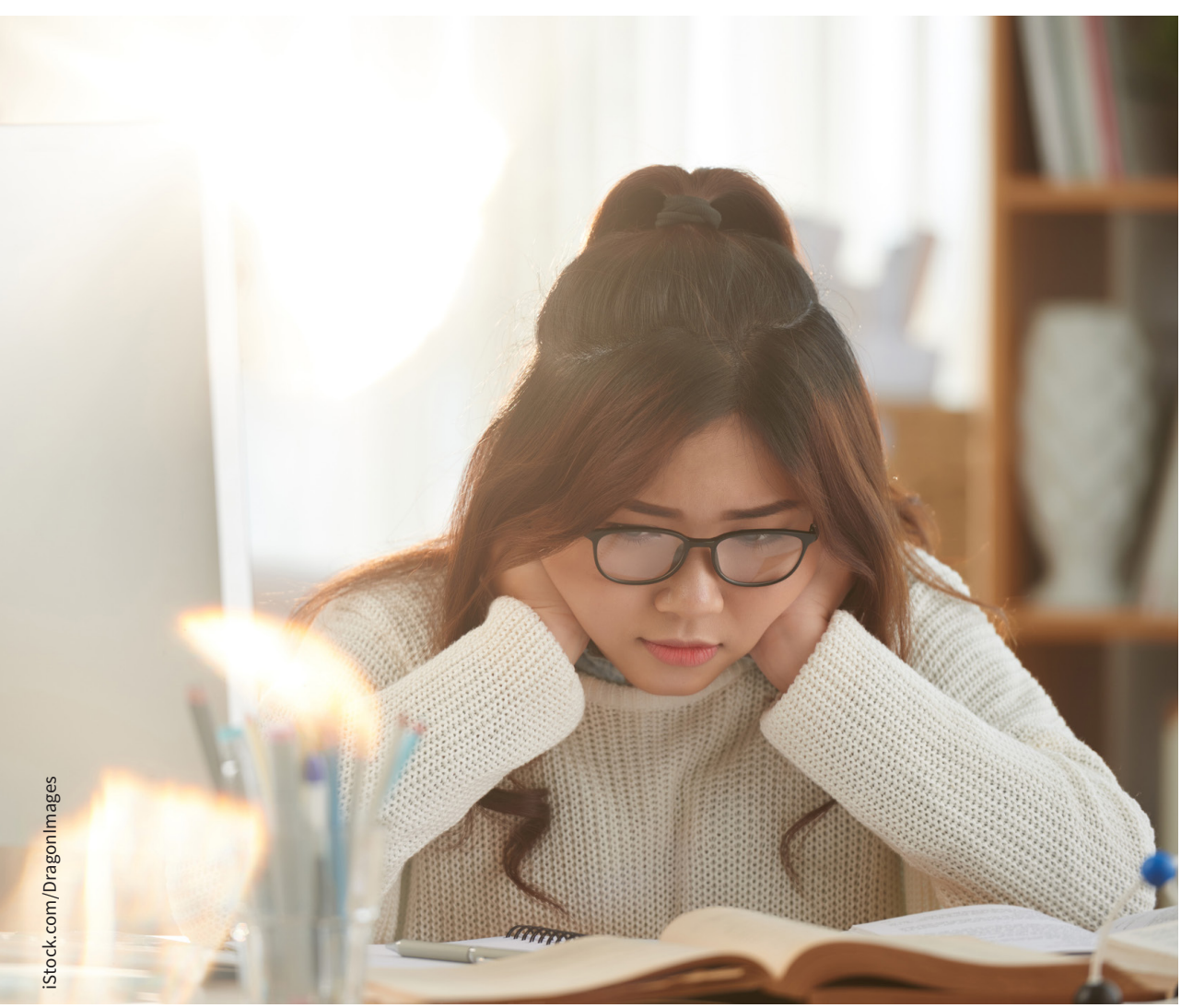

Many trainees were already grappling with financial challenges before COVID-19 broke out. directly to faculties of medicine to support their students and residents.

Victor Do, president of the Canadian Federation of Medical Students (CFMS), says many medical students were already grappling with financial challenges before COVID-19 broke out. Students often rely on summer jobs to help cover their tuition and living costs, but it's unclear when most workplaces will reopen. Meanwhile, those living on campus have been forced to find new accommodations as universities have shut down.

According to Do, the grant from CMAF will "make a dent" in the unexpected expenses that trainees are facing because of the pandemic, especially if most of the money is channelled into direct aid, such as bursaries. However, he also called for "longer term, systemic change" to reduce financial pressure on medical learners, including reconsidering the overall cost of medical training and enhancing mental health supports.

Do said he expects to see increased levels of distress among trainees in the fall as medical learners return to training and tuition payments come due. "It's not just about the support they're going to get now but ensuring that, as they return to whatever new normal, students are getting support then as well," he explained.

In addition to the grant to support medical learners, CMAF committed an additional $\$ 15$ million for community hospitals, primary care innovation, and supports for front-line health care workers, including counselling and accommodation for those who need to self-isolate.

Lea Batara, CMAJ 